\title{
Identification and Comparative Analysis of Essential Performance Indicators in Two Levels of Soccer Expertise
}

\author{
M. R. Abdullah", A. B. H. M. Maliki", R. M. Musa", N. A. Kosni", H. Juahir ${ }^{*}$, S. B. Mohamed* \\ ${ }^{\#}$ Faculty of Applied Social Sciences, Universiti Sultan Zainal Abidin, 21300 Terengganu, Malaysia \\ E-mail:mdrazali896@gmail.com,bisyrihusin84@gmail.com,rabiumuazu86@gmail.com,azuralaila@yahoo.com
}

*East Coast Environmental Research Institute (ESERI), Universiti Sultan Zainal Abidin, 21300 Terengganu, Malaysia

E-mail:hafizanj@gmail.com, saifulbahri@unisza.edu.my

\begin{abstract}
This study aims to identify the essential performance indicators in two level of soccer expertise. A total of 84 elite's soccer players and 100 novice players from eight soccer academies in Malaysia were enrolled and subjected to standard anthropometric, fitness, skills related performance testing and responded to the questionnaire in mastery and performance. Principal component analysis (PCA) was employed to determine the most indispensable variables pertinent to the requirement of the game in relation to the level of expertise of the players. The initial PCA shows seven components out of 26 as the most significant for both elite and novice soccer players with a considerable eigenvalue $>1$. Moreover, the PCA after varimax rotation highlighted seven principles components (PCs) for elite and novice players respectively. Each of the seven components contained varifactors (VF) selected based on their higher factor loading and that distinguish the players on their expertise. The first PCs for elite's players revealed strong loading from sit and reach $(0.780)$, vertical jump $(0.635), \mathrm{VO}_{2 \max }(0.637)$ and age $(0.752)$. The second PCs revealed weight $(0.639)$, biceps $(0.859)$, triceps $(0.769)$, subscapular $(0.847)$, suprailiac $(0.886)$ and middle upper arm circumference $(0.776)$. The third PCs revealed 505 agility $(0.618), 5 \mathrm{~m}$ speed $(0.712), 10 \mathrm{~m}$ speed $(0.858)$ and $20 \mathrm{~m}$ speed $(0.929)$. The forth PCs revealed task $(-0.675)$ and short pass $(0.789)$ and the last PCs revealed sit up (-0.702). For novice's players, the first PCs revealed vertical jump (0.624), weight (0.861), height (0.856), sitting height $(0.632)$, middle upper arm circumference $(0.673)$, calf circumference $(0.790)$ and maturity $(0.651)$. The second PCs revealed biceps $(0.832)$, triceps $(0.899)$, subscapular $(0.816)$ and suprailiac $(0.869)$. The third PCs revealed $5 \mathrm{~m}$ speed $(-0.847), 10 \mathrm{~m}$ speed (-0.877), 20m speed (-0.785) and $\mathrm{VO}_{2 \max }(\mathbf{0 . 6 5 8})$. The forth PCs revealed task (0.694) and ego (0.747) and the last PCs revealed short pass $(\mathbf{0 . 7 6 6 )}$.
\end{abstract}

Keywords - elite players; novice players; soccer; principal component analysis; performance indicators

\section{INTRODUCTION}

Performance in soccer is a custom requiring a multitude of abilities that is profoundly reliant upon an unpretentious mix of players' physical fitness, bodily characteristics, strategy, tactical ability, technical skills as well as psychological abilities [1]. At both levels of participation, experts, coaches, specialists and sports researchers continue to investigate consistently and enhance these diverse areas of performance for accomplishment either in part or parcels. As a guide to accomplish this, performance analysis provides an actual record of series of events covering both individual and team performance with the view of providing insights into the capability, strength or weakness of the team or an individual [2]. It has in fact been the basis for drawing conclusion, provision of feedback on performance and making an informed decision. It also served as a guide to dissecting efficient technique for improving technical, tactical, psychological and physical skills in soccer for which has all been part of the coaching process. Within any confirmatory-based system for soccer games performance, learning of the physiological, tactical, technical and psychological prerequisites is desirable to assist in the configuration and utilization of sufficient preparation in planning for the contemporary match [3]. In fact, research in male soccer has demonstrated that the physical qualities of tactical, technical and psychological of players to meet the demand of the game during competition have considerably developed over late decades [4], [5]. These demands allude to an extensive variety of qualities that are crucial in helping players in seeking for ownership of the ball, responding rapidly and ideally to ceaselessly changing game circumstances and sustaining high-performance levels all throughout the duration of game period and over the competitive season [6]. Therefore, a careful comprehension of the athletic necessities particular to match play and elements influencing successful performance can guarantee that right, and reasonable assessments are taken for organizing the physiological, physical, tactical, technical and 
psychological components of preparing training programmes towards the development of the players.

Generally, the system structure of any physiological, physical, tactical, technical and psychological regimen across all level of participation should guarantee that a suitable and correlative blend of these segments is furnished to adapt to the specific prerequisites of play. Without a doubt, the improvement system in soccer alludes to the different components supporting the programme namely physical components comprising fitness such as endurance, agility, balance flexibility, speed, body characteristics such as age, weight, height, body mass index, skills, creativity and psychological components such as mastery, perseverance and readiness to perform [7]. It is necessary to utilize sound investigative criterions of these components with a specific end goal to upgrade sports performance. As a major aspect of the coaching process, exact data from examinations of performance in competition is fundamental to give a stage whereupon target assessments for drill and arrangement can be made. The part of the sports scientist in this procedure, in soccer, is to be the vehicle for interfacing novel innovation and research with practice and play in the setting of the game [8].

Principal component analysis (PCA) is a robust statistical technique that involves recognition of pattern from an observed group or any given parameters. It offers insights into essential components through considering the spatial and temporal variability that explains an entire data set and consequently excluding the less essential components without loss of the original information from the data [9]. PCA is extremely important in extracting the most needed information from a large volume of data set. This can assist in saving time, cost and energy since the original information is often retained. The use of PCA is considerably new in the area of sports and exercise science [6]. Nevertheless, numerous study reported that the dimension of a huge data set could be trimmed down by using PCA which is considered as one of the most prevalent and useful statistical methods for uncovering the potential structure of a set of variables [10], [11]. This method is used for explaining the variance of a large set of interrelated variables by transforming them into a new, smaller set of uncorrelated (independent) variables namely principal components (PCs). PCs are orthogonal and uncorrelated to each other and have linear combinations of the original variables [9].

In the game of soccer during training and real match day, numerous components can or will directly or indirectly impact player's productivity and obviously the last result. These numerous components can be well digested and applied when broken down into the most essential that determine the outcome of the match. This article aims to identify the variables that are essential in the performance of the game in view of the level of participation by employing PCA.

\section{MATERIAL AND METHOD}

\section{A. Participants}

A total of 184 players were recruited to participate in this study. The players were elite (84 players, $15.48 \pm 1.47)$ and novice (100 players, $14.88 \pm 1.68)$ drawn from eight Malaysian state soccer academy for both elite and novice players. Two out of the eight soccer academies were for elites, and six were for novices respectively. The coaches and the managers of the academies were informed about the purpose of the research. Writing approval was obtained, and all the players signed consent forms.

\section{B. Battery Test}

Standard anthropometric testing was conducted which constitutes of weight, height, sitting height and body fat $\%$. Standing height was measured with a wall-mounted wooden stadiometer to the nearest $0.5 \mathrm{~cm}$. Body weight was evaluated with a standardized electronic digital scale to the nearest $0.01 \mathrm{~kg}$. Sitting height was tested from the vertex of the head to the seated buttocks and was recorded to the nearest $0.5 \mathrm{~cm}$ [12]. Skinfold caliper was used to measure the triceps, biceps, subscapular and suprailiac to the nearest $0.1 \mathrm{~mm}$ whereas medial upper arm circumference (muac) and calf circumference (cc) were measured via measuring tape. From these characteristics, the body mass index was then computed by dividing the body mass $(\mathrm{kg})$ and body height squared $\left(\mathrm{m}^{2}\right)$ [13]. All the measurements were executed in accordance with ISAK protocol [14]. The measurements were obtained twice, and the mean value was generated as the final score.

The test was performed according to the recommended method for physical fitness tests [15]. Participants lay on their back with their knees bowed at around right edges while both feet were situated level on the floor. They held their hands against their chest where they should stay throughout the test. In the test process, a supporter held the participants' feet put on the ground. Participants sat up until they touched their knees to both elbows; then, they came back to the floor. The movement was frequented as many times as possible under the period for $60 \mathrm{~s}$. The aide totaled and recorded the quantity of right finished sit-ups. The test was measured just once attributable to the impact of exhaustion.

The multistage $20-\mathrm{m}$ shuttle run test was implemented to acquire the participant's maximal oxygen uptake [16]. Every athlete kept running for whatever length of time he/she could afford until could no more keep pace with the velocity of the tape. Test results for every participant were expressed as an anticipated $\mathrm{VO}_{2 \max }$ accomplished by checking the last level and ended shuttle number at the time when the participant voluntarily resigned from the test. In spite of the fact that motivation and drills of the participants might influence their scores, it is still a legitimate test in assessing maximum oxygen uptake and can be performed in considerably a large number of participants minimizing expenses and time.

Linear sprint speed was evaluated over $30 \mathrm{~m} \mathrm{[17].}$ Infrared speed trap (brower timing system) was positioned at the start line $(0 \mathrm{~m})$ and $5 \mathrm{~m}, 10 \mathrm{~m}$ and $20 \mathrm{~m}$ at the height of around $0.5 \mathrm{~m}$ off the ground. Subjects started the test from a standing start at a distance of $0.3 \mathrm{~m}$ behind the initial timing gate before starting the test taking after a countdown from the lead researcher. The subjects were told to keep running at maximal velocity throughout the full length of time of the sprint test. To avoid a reduction in sprint speed on approach to the $20 \mathrm{~m}$ gate, a member of the coaching staff who stood 
on a marker $2 \mathrm{~m}$ beyond the final timing gate provided verbal encouragement throughout each effort. The subjects were told to keep up the maximal pace until passing the marker on which the mentor stood. The execution times were recorded at situated on 5, 10 and $20 \mathrm{~m}$ respectively. Players performed two reiterations with the best (fastest) times utilized for statistical analysis. At least $4 \mathrm{~min}$ of restoration were given between repetitions.

A Vertec testing gadget (M-F Athletic Co., Cranston, Rhode Island) was utilized to decide vertical jump height $(\mathrm{cm})$, a legitimate and solid measure of lower body power [18]. To surface this test, a prepared tester attuned the height of the color-coded plastic vanes such that it paralleled to the athlete's standing reach height. The vane stack was then raised a standardized distance (corresponding to the participants' anticipated jump), so the participant would not jump higher or lower than the arrangement of vanes. Utilizing a countermovement, the participant flexed the ankles, knees, and hips and swung the arms in an upward movement tapping the highest conceivable vane with the fingers of the dominant hand. Every participant performed three jumps with 40-60 seconds rest between every jump. The best of two trials was recorded and utilized for statistical analysis.

The flexibility of the lower back and hamstrings was measured by the sit and reach test. The athletes performed two trials, and the best one was recorded for further analysis [19].

Agility was determined by the 505 agility test. The protocol was conducted as previously described [20]. Pointers are set up 5 and 15 meters from a line marked on the ground. The participant runs from the $15 \mathrm{~m}$ marker near the line (run in distance to form up speed) and via the $5 \mathrm{~m}$ markers, turns on the line and runs back over the $5 \mathrm{~m}$ markers. The time is documented using infrared speed trap (brower timing system) from when the athletes first run through the $5 \mathrm{~m}$ marker and stopped when they return through these markers. Each subject performed two maximal attempts and the fastest time was recorded for further analysis. The athletes should be encouraged not to overstep the line by too much, as this will increase their time.

Stage of pubic hair based on the criteria of Tanner was used as an indicator of sexual maturity status [21]. Furthermore, basic skills test for ball control, short pass and long pass basic tests were administered to the players. The basic skills were selected and implemented according to the guidelines provided by FMAC battery test [22].

This test allows assessment of coordinated dribbling under time pressure and assessment of speed. On the signal "Ready-Go", the player starts with the ball from behind line marked. After 5 meters he dribbles to the right, around the first post of a triangle (2). Following the set order, he dribbles around the other posts. After 10 meters he dribbles around a block (3). Then, after 8 meters he plays the ball around one side of a square (4) and runs around the other side (5) to collect it (6). Then, he sprints through a gate and puts his foot on the ball (7). The examiner measures the time taken for the "Go" signal until the player has the ball under his foot. The test is made with a stopwatch in units of 0.1 seconds.
This test allows assessment of accuracy and coordination in passing a moving ball. The player dribbles the ball within a marked rectangle up to a line and from there passes accurately into a hockey goal 11 meters away. The examiner measures a total of five attempts, scoring 3 points if the ball goes into the goal and 1 point if the ball hits the crossbar or goal post.

This test allows assessment of passing accuracy and shooting power over a long distance. The player passes the ball from its dead position on the line into a circle (radius: 2 meters, distance: 36 meters) marked in the middle of a square target area $(10 \times 10$ meters $)$. The player has a trial attempt first. The examiner measures a total of five attempts. The measurement unit is in point; 3 if the ball lands in the circle or touches its circumference and 1 point if the ball lands elsewhere in the square.

The test allows assessment of accuracy and coordination in shooting from a dead ball. A ball is placed 16 meters from the middle of the goal. The player shoots into the goal, which is divided into six segments. He aims first for the top right, then for the top left segment. The examiner measures a total of three attempts each at the top right and top left segments. Three points are scored if the player shoots into the correct segment, 1 point if the player hits the crossbar or goalpost of this segment, 1 point if the player shoots into the top middle segment and 0 points for shooting into the lower segments.

This test allows assessment of accuracy and coordination in shooting from a ground pass. The examiner plays a 20meter ground pass from the edge of the penalty area, level with the goalkeeper's box, to the penalty spot. After a short run-up, the player shoots into the goal, which is divided into six segments. If the pass is not accurate enough, then the attempt is repeated. The examiner measures a total of five attempts, scoring 6 points if the player shoots into the top right or left segments, 1 point if the player hits the cross bar or goalpost of these segments, 2 points if he shoots into the top middle segment and 1 point if he shoots into the lower segments.

Questionnaire for achievement in mastery and performance (TEOSQ) was used to ascertain the degree of the player's mastery and performance [23].

\section{Data and Data Pre-Treatment}

A total of 4784 matrices data points (26 variables $\times 184$ data set) were operated in this analysis. The total of missing data was very small $(\sim 3 \%)$ compared to the overall data. In order to facilitate the data analysis, the nearest neighbor method was applied to the study [9]. This method examines the distance between each point and the closest point to it. The nearest neighbor method is the simplest scheme, where the end points of the gaps are used as estimates for all missing values [9]. The equation applied in this method is shown as follows

$$
y=y_{1} \text { if } \leq x_{1}+\frac{x_{2}-x_{1}}{2}
$$

or

$$
y=y_{2} \text { if } x \leq x_{1}+\frac{x_{2}-x_{1}}{2}
$$


where $y$ is the interpolant, $x$ is the interpolant of the time point, while, $y_{1}$ and $x_{1}$ are the range of coordinates for the starting point of the gap, the opposite for ending points of the gap is $y_{2}$ and $x_{2}$.

PCA can recognize the most significant variables pattern which can indicate the key source of relative performance indicators. Because of this reason, the current study utilised PCA through the selection of variables that have a high factor loading with an eigenvalue greater than 1 and the less with eigenvalue lower than 1 are eliminated from the data set. This enabled the researchers to obtain the data with a minimal loss of original data [24]. Therefore, the relative performance indicators variables were standardized through a $Z$-scale transformation to a mean of 0.0 and variance of 1.0 by applying equation as follows

$$
Z_{i j}=\left(X_{i j}-\mu\right) / \sigma
$$

where $Z_{i j}$ is the $j_{t h}$ value of the standardize score of the measured variable $i$, meanwhile $X_{i j}$ is the observation of $j_{t h}$ on $i$ variable, $\mu$ is the mean value of the variable's, and $\sigma$ is the standard deviation.

The Z-scale modification technique was utilized to guarantee that the distinctive relative performance indicators variables had similar weights in the statistical analysis procedure. Moreover, these modifications will homogenize the fluctuation of the distribution and avert any classification errors that may occur from groups defined by variables of completely different sizes [25]. At that point, the data matrix was decomposed into scores or components and loadings (relationships between the original variables and the new PCs that extracted from the analysis) for the variables. Bartlett's test of sphericity was performed at the start of the PCA to inspect the relationship between the variables utilized as a part of the PCA [26]. This test was able to estimate the probability that there were correlations in a matrix [27]. Null hypothesis $\left(H_{0}\right)$ in this test states that there is no correlation significantly different from 0 between the variables, while the alternative hypothesis $\left(H_{a}\right)$ states that at least one of the correlations between the variables is significantly different from 0 . As the computed $p$-value is lower than the significant level of alpha $=0.05$, one should reject $H_{0}$, and accept the alternative hypothesis. The risk to reject the $H_{o}$, while it is true is lower than $0.01 \%$. When the null hypothesis is rejected, then, it is confirmed that the variables used in the PCA are correlated. The Kaiser-MeyerOlkin (KMO) test was carried out to measure the sampling adequacy. These matrices measure the sampling adequacy for each variable along the diagonal and the negatives of the partial correlation/covariance on the off-diagonals. The diagonal elements should be greater than 0.5 at a bare minimum if the sample is adequate for a given pair of variables [28]. If any pair of variables has a value which is less than 0.5 , consider dropping one of them from the analysis. The PCs generated by PCA sometimes are not readily interpreted and should be rotated using any of a number of applicable methods such as varimax rotation. The goal of varimax rotation is to decrease the density of the components by transforming the huge loadings larger and the small loadings smaller within each component. The varimax rotation method was applied because this method simplifies the factor structure and, therefore, makes its interpretation easier and more reliable. In the varimax rotation method, only the PCs with eigenvalues greater than 1 are used and considered significant [29] and to construct the new variables which were known as varifactors (VFs) or factor loadings. This approach is known as the Kaiser Criterion. The Kaiser Criterion is used to solve the problem of the number of components to be retained [30]. The numbers of VFs extracted by varimax rotations are equal to the number of variables in agreement with common features and can include unobservable, hypothetical, and latent variables. The VFs are values that are used to measure the correlation between variables. VF values which are greater than 0.75 are considered "strong," the values ranging from 0.50 to $0.75(0.50 \geq$ factor loading $\geq 0.75)$ are considered "moderate," and the values ranging from 0.30 to 0.49 ( $0.3 \geq$ factor loading $\geq 0.49$ ) are considered "weak" factor loadings [31]. In this study, the VFs with absolute values greater than 0.60 were standardized as the selection threshold. All the analysis was conducted using XLSTAT version 2014 USA.

\section{RESULTS AND DISCUSSION}

Table 1 shows the Kaiser-Meyer-Olkin (KMO) measure of sampling adequacy. The current study carried out the test to determine the adequacy of the sampling to measure and to make a reasonable interpretation based on the data gathered [28]. Also, we implemented the test to ensure that the variables are not related to each other. From the table, the KMO value shows 0.73 and 0.70 which contributed $73 \%$ and $70 \%$ sampling adequacy for both the novice and elite players respectively. Based on this result, it is evident that there is no multicollinearity observed among the original variables and that enabled us to proceed further with the analysis having satisfied the measure of the sampling adequacy. Fig. 1 projects the eigenvalue for the novice and elite players. From the figure, it can be observed that only seven components out of the 26 were identified by the PCA for both novice and elite as the most essential due to their higher eigenvalues greater than 1 . These components were retained and utilized as an input variable for further analysis.

Fig. 1 shows the eigenvalue for the novice and elite players of soccer. Through the figure, it can be spotted that seven PCs in total were identified by PCA for both novice and elite soccer players as the most essential due to higher eigenvalue that greater than 1 . These PCs retained and utilized as an input variable for further analysis.

Fig. 2 projects the most significant PCs for novice and elite soccer players after varimax rotation. Additionally, the contribution of each varifactor within the PCs as well their variability is shown. It can be observed from the figure that VF1 and VF2 contributed to about $31.96 \%$ of the total data set and the variability of $19.31 \%$ and $12.65 \%$ for novice soccer players. However, VF1 and VF2 for elite soccer players contributed to about $30.02 \%$ of the whole data set with a variability of $12.88 \%$ and $17.14 \%$ respectively. 
TABLE I

KAISER-MEYER-OLKIN (KMO) MEASURE OF SAMPLING ADEQUACY

\begin{tabular}{|l|l|l|}
\hline Variables & Novice & Elite \\
\hline V Sit and Reach & 0.859 & 0.753 \\
\hline Sergeant Jump & 0.727 & 0.859 \\
\hline Sit Up Variation & 0.656 & 0.473 \\
\hline Agility & 0.551 & 0.595 \\
\hline Speed 5m & 0.671 & 0.649 \\
\hline Speed 10m & 0.715 & 0.696 \\
\hline Speed 20m & 0.859 & 0.646 \\
\hline VO2max & 0.821 & 0.615 \\
\hline Age & 0.852 & 0.751 \\
\hline Weight & 0.657 & 0.724 \\
\hline Height & 0.701 & 0.514 \\
\hline Sitting Height & 0.610 & 0.724 \\
\hline Bicep & 0.774 & 0.830 \\
\hline Tricep & 0.669 & 0.778 \\
\hline Subscapular & 0.756 & 0.801 \\
\hline Suprailiac & 0.752 & 0.826 \\
\hline MUAC & 0.861 & 0.698 \\
\hline CC & 0.730 & 0.816 \\
\hline Maturity & 0.879 & 0.754 \\
\hline Task & 0.257 & 0.413 \\
\hline Ego & 0.529 & 0.504 \\
\hline Ball Control & 0.516 & 0.691 \\
\hline Long Pass & 0.894 & 0.700 \\
\hline Short Pass & 0.503 & 0.705 \\
\hline Shooting RTC & 0.593 & 0.696 \\
\hline Shooting LTC & 0.454 & 0.545 \\
\hline KMO & 0.730 & 0.706 \\
\hline & & \\
\hline
\end{tabular}

Novice
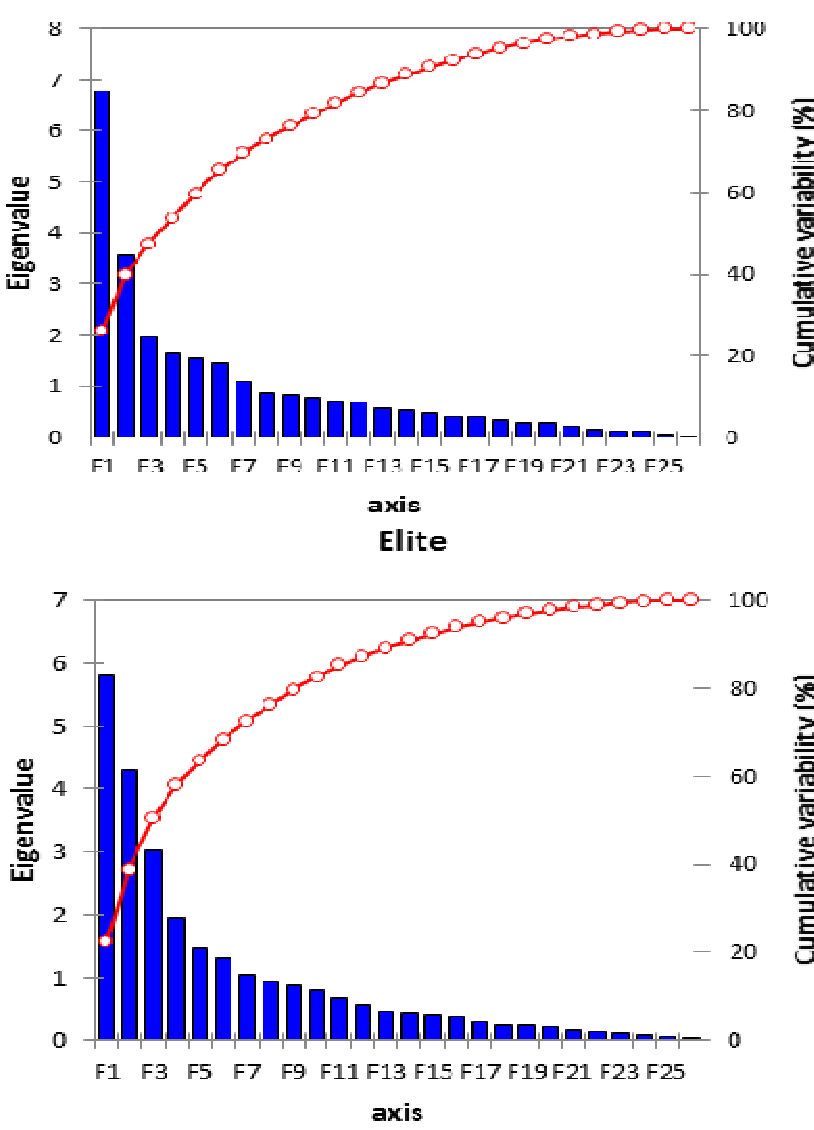

Fig. 1 Eigenvalue for the novice and elite players
Table 2 revealed that seven out of 26 performance indicators satisfy the 0.60 -factor loading threshold for both novice and elite soccer players respectively. These indicators are then classified as the essential components that are mainly required for the performance in soccer game across the two levels of expertise. However, each of these components contained varifactors related to it.

Fig. 3 indicates the similarities and differences on the essential performance between novice and elite soccer players. Only first PCs retrieved into these whiskers plots due to highest loading factor. From the figure, it can be seen that the mean of elite soccer players is slightly higher than novice soccer players in all the components examined. This explains that the need for the physical fitness related components are more pronounced in soccer elite soccer players as opposed to novice soccer players due to the nature of the diverse competitions both players participate in.

This study aims to identify the variables that are essential in the performance of soccer game for both elite and novice players. To achieve the aim of this study, we employed 84 elite's soccer players and 100 novice players from eight soccer academies in Malaysia. We subjected the participants to standard anthropometric, fitness, skills related performance testing and responded to the questionnaire in mastery and performance. We utilized PCA to determine the most crucial variables pertinent to the requirement of the game in relation to the level of expertise of the players.
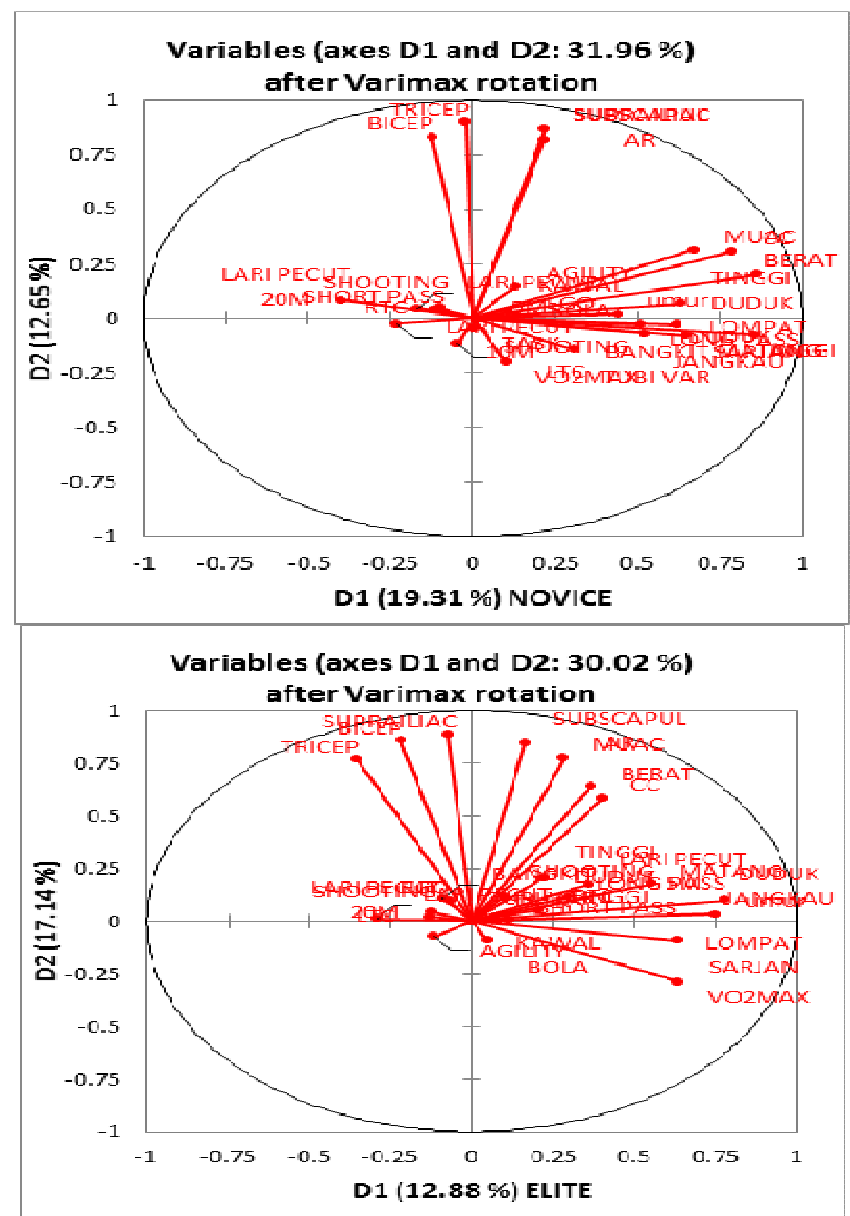

Fig. 2 Factor loading plot after varimax rotation for the novice and elite players 
TABLE II

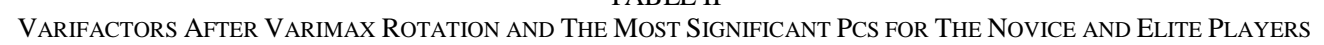

\begin{tabular}{|c|c|c|c|c|c|c|c|c|c|c|c|c|c|c|}
\hline \multirow{2}{*}{ Variables } & \multicolumn{7}{|l|}{ Novice } & \multicolumn{7}{|l|}{ Elite } \\
\hline & D1 & D2 & D3 & D4 & D5 & D6 & D7 & D1 & D2 & D3 & D4 & D5 & D6 & D7 \\
\hline VS\&R & 0.522 & -0.072 & 0.177 & 0.199 & 0.153 & 0.050 & -0.104 & 0.780 & 0.102 & 0.100 & -0.002 & -0.061 & -0.030 & 0.123 \\
\hline $\mathrm{VJ}$ & 0.624 & -0.028 & -0.284 & 0.256 & -0.102 & 0.125 & 0.069 & 0.635 & -0.091 & -0.199 & 0.063 & -0.161 & 0.062 & 0.326 \\
\hline SUP & 0.309 & -0.143 & 0.162 & -0.443 & 0.133 & -0.184 & 0.329 & -0.088 & 0.108 & -0.028 & 0.154 & -0.702 & -0.534 & 0.117 \\
\hline $505 \mathrm{~A}$ & 0.130 & 0.147 & 0.068 & -0.024 & -0.083 & 0.858 & 0.065 & -0.117 & -0.071 & 0.618 & 0.073 & 0.022 & -0.159 & -0.170 \\
\hline S5 & -0.168 & 0.046 & -0.847 & 0.002 & 0.046 & 0.222 & -0.119 & 0.362 & 0.175 & 0.712 & 0.163 & 0.035 & 0.329 & -0.060 \\
\hline $\mathrm{S} 10$ & -0.229 & -0.026 & -0.877 & -0.085 & 0.044 & -0.166 & -0.016 & -0.294 & 0.009 & 0.858 & -0.123 & -0.013 & 0.144 & 0.051 \\
\hline $\mathrm{S} 20$ & -0.397 & 0.082 & -0.785 & -0.040 & 0.080 & -0.189 & -0.021 & -0.123 & 0.042 & 0.929 & -0.030 & -0.049 & 0.159 & -0.023 \\
\hline YYIE1 & 0.101 & -0.200 & 0.658 & 0.066 & 0.074 & 0.382 & 0.126 & 0.637 & -0.287 & -0.113 & 0.083 & 0.263 & -0.199 & -0.037 \\
\hline AGE & 0.441 & 0.020 & 0.464 & 0.101 & 0.040 & 0.577 & -0.021 & 0.752 & 0.034 & -0.221 & 0.101 & 0.320 & 0.046 & 0.277 \\
\hline $\mathrm{W}$ & 0.861 & 0.202 & 0.203 & -0.092 & -0.159 & -0.023 & 0.013 & 0.367 & 0.639 & -0.210 & -0.059 & -0.088 & 0.094 & 0.550 \\
\hline $\mathrm{H}$ & 0.856 & -0.075 & 0.155 & -0.067 & 0.077 & 0.156 & 0.009 & 0.208 & 0.052 & -0.071 & 0.006 & -0.072 & 0.153 & 0.849 \\
\hline $\mathrm{SH}$ & 0.632 & 0.066 & 0.223 & -0.010 & 0.390 & 0.179 & -0.237 & 0.223 & 0.206 & -0.101 & -0.009 & 0.043 & 0.024 & 0.873 \\
\hline B CEP & -0.124 & 0.832 & -0.243 & -0.001 & 0.021 & 0.013 & -0.034 & -0.217 & 0.859 & 0.221 & -0.047 & -0.067 & 0.054 & -0.076 \\
\hline T CEP & -0.023 & 0.899 & -0.080 & -0.014 & 0.006 & -0.090 & -0.009 & -0.355 & 0.769 & 0.212 & -0.004 & -0.024 & 0.046 & 0.020 \\
\hline SUBS & 0.216 & 0.816 & 0.113 & -0.003 & 0.073 & 0.141 & -0.043 & 0.165 & 0.847 & -0.122 & -0.015 & 0.155 & 0.051 & 0.079 \\
\hline SUPR & 0.221 & 0.869 & -0.010 & 0.014 & -0.017 & 0.084 & -0.035 & -0.073 & 0.886 & 0.101 & -0.021 & 0.023 & -0.034 & -0.004 \\
\hline MUAC & 0.673 & 0.313 & 0.182 & -0.061 & -0.152 & -0.096 & -0.101 & 0.282 & 0.776 & -0.208 & 0.084 & -0.207 & 0.064 & 0.206 \\
\hline $\mathrm{CC}$ & 0.790 & 0.306 & 0.275 & -0.070 & -0.004 & -0.051 & -0.063 & 0.403 & 0.583 & -0.204 & -0.079 & 0.000 & 0.055 & 0.340 \\
\hline MATURITY & 0.651 & -0.081 & 0.265 & -0.039 & 0.056 & 0.432 & 0.060 & 0.551 & 0.178 & -0.207 & 0.245 & 0.229 & 0.212 & 0.252 \\
\hline TASK & 0.005 & -0.047 & 0.006 & 0.694 & 0.134 & 0.095 & -0.006 & 0.034 & 0.037 & -0.127 & -0.675 & 0.234 & -0.054 & -0.179 \\
\hline EGO & 0.130 & 0.010 & 0.207 & 0.747 & 0.021 & -0.219 & -0.006 & -0.066 & 0.095 & -0.203 & -0.173 & -0.505 & 0.282 & -0.523 \\
\hline B CT & 0.111 & 0.030 & -0.145 & 0.158 & 0.612 & -0.355 & -0.123 & 0.048 & -0.091 & -0.110 & 0.748 & 0.154 & 0.241 & -0.082 \\
\hline L P & 0.514 & -0.030 & 0.224 & 0.163 & -0.162 & 0.078 & 0.401 & 0.296 & 0.117 & -0.154 & 0.533 & 0.540 & 0.039 & 0.005 \\
\hline S P & -0.113 & 0.039 & 0.000 & 0.034 & 0.766 & 0.095 & 0.243 & 0.116 & 0.003 & 0.049 & 0.789 & 0.058 & 0.096 & -0.047 \\
\hline S RTC & -0.100 & 0.048 & 0.080 & 0.028 & 0.226 & 0.030 & 0.791 & 0.100 & 0.118 & 0.073 & 0.212 & 0.032 & 0.660 & 0.142 \\
\hline S LTC & -0.046 & -0.114 & 0.033 & -0.114 & -0.068 & 0.059 & 0.772 & -0.130 & 0.020 & 0.153 & 0.201 & 0.043 & 0.749 & 0.020 \\
\hline Eigenvalue & 6.769 & 3.567 & 1.968 & 1.644 & 1.557 & 1.473 & 1.094 & 5.807 & 4.299 & 3.013 & 1.956 & 1.449 & 1.299 & 1.046 \\
\hline Variability $(\%)$ & 19.308 & 12.652 & 13.032 & 5.593 & 5.205 & 7.203 & 6.518 & 12.88 & 17.138 & 11.653 & 8.500 & 5.655 & 6.740 & 10.011 \\
\hline Cumulative \% & 19.308 & 31.960 & 44.991 & 50.585 & 55.789 & 62.992 & 69.510 & 12.88 & 30.018 & 41.671 & 50.171 & 55.826 & 62.566 & 72.577 \\
\hline
\end{tabular}

Note: VS\&R = V sit and reach, VJ = Vertical jump, SUBS = Subscapular, 505A= 505 Agility, S5=5m speed, S10=10m speed, S20= 20m speed, YYIE1= Yoyo endurance level 1 , Age = Age in years, $\mathrm{W}=\mathrm{Weight}, \mathrm{H}=$ height, $\mathrm{SH}=$ Sitting height, $\mathrm{B}$ CEP $=$ Biceps, $\mathrm{T}$ CEP $=$ Triceps, $\mathrm{SUPR}=$ Suprailliac, MUAC = Medial upper arm circumference, $\mathrm{CC}=\mathrm{Calf}$ circumference, $\mathrm{B}$ CT $=\mathrm{Ball}$ control, $\mathrm{L} \mathrm{P}=\mathrm{Long}$ pass, $\mathrm{S} \mathrm{P}=\mathrm{Short}$ pass, $\mathrm{S}$ RTC $=$ Shoot at right top corner, $\mathrm{S}$ LTC $=$ Shoot at left top corner. 


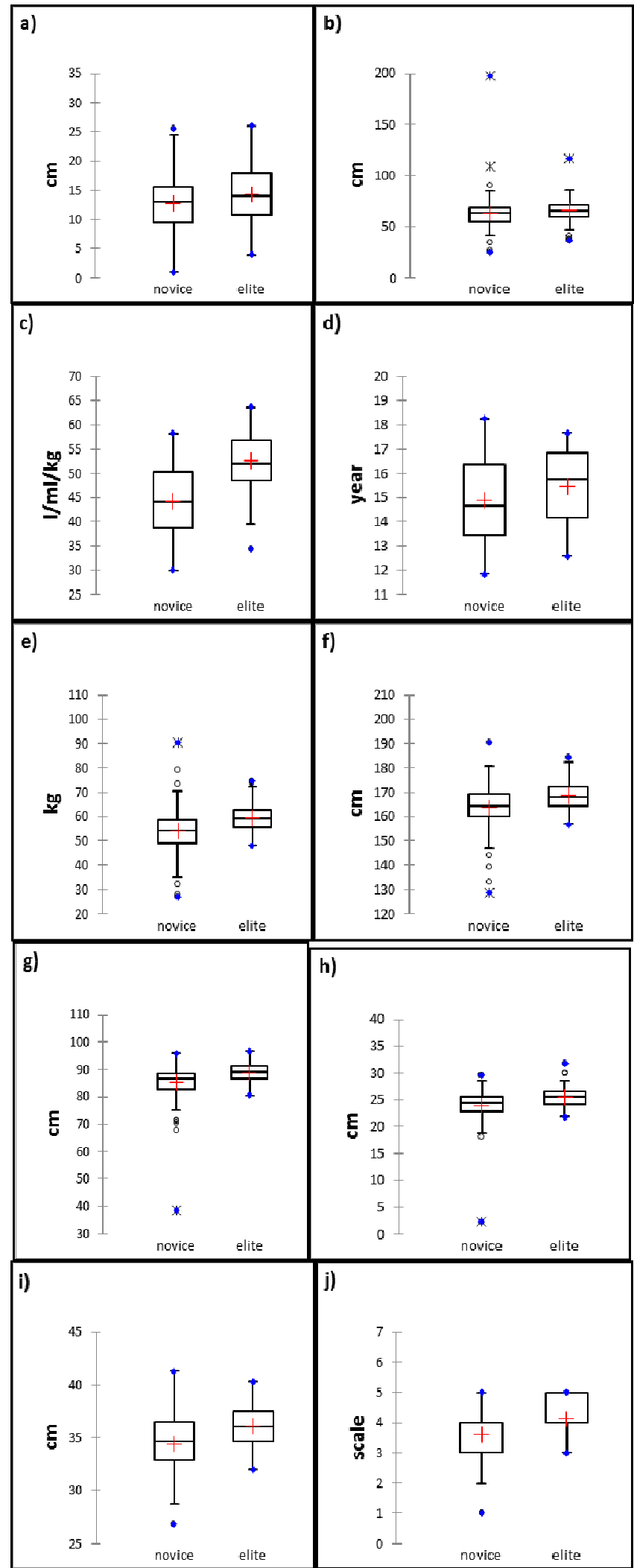

Fig. 3 Box and whisker plots of the similarities and variabilities' of the physical fitness related components between the two levels of soccer players. (a) V sit and reach, (b) vertical jump, (c) yoyo test, (d) age, (e) weight, (f) height, (g) sitting height, h) medial upper arm circumference (MUAC), (i) calf circumference (cc) and (j) maturity

\section{A. Performance Source of Variation: Novice Soccer Players}

In the current study, VFs with absolute values greater than 0.60 were standardized as the selection threshold due to the fact that these values are considerably solid and stable which indicates moderate to strong loadings on the extracted factors. Table 2 and Fig. 2 revealed that seven out of 26 performance indicators satisfy the 0.60 -factor loading threshold for both novice and elite soccer players respectively. These indicators are then classified as the essential components that are mainly required for the performance in soccer game across the two levels of expertise. However, each of these components contained varifactors associated to it. For the novice players, the VF1 contributes for about $19.31 \%$ of the variation in the performance indicators data. It has high positive loading from seven variables which are height (0.856), sitting height (0.632), sergeant jump (0.624), weight (0.861), medial upper arm circumference (0.673), calf circumference (0.790) and maturity (0.651). Considering the nature of these seven components, they can be interpreted as physical characteristics component.

A lot of studies in various types of sports have stressed the importance of body characteristics such as maturity height and weight for soccer players [32], [33]. Bodily characteristics can distinguish successful soccer players from none successful in the particular positional role in the game of soccer [34].

The VF2 accounted for $31.96 \%$ variability of the data. It projects high positive loading from four components namely; biceps (0.832), triceps (0.899), subscapular (0.816) and suprailiac (0.869) that are closely related to body composition. The variables have been identified as one of the frequently utilized methods for analyzing nature of body build. Because of its significance, body composition has been used to study several aspects of sports and exercise science that can be useful in drawing out talented athletes for a particular sport. Certain variables such as bicep, triceps, and body mass have been currently discovered between novice soccer players of varying positions predicting that players of certain size and shape may be appropriate for the needs of the variety of positions [35].

The VF3 demonstrates $44.99 \%$ of the variance in the data. It shows high positive and negative loading from $5 \mathrm{~m}$ speed $(-0.847), 10 \mathrm{~m}$ speed (-0.877), 20m speed (-0.785) and VO2max (0.658) which are attributed to endurance. Although all the speed values show negative signs, it means that cardiovascular endurance is inversely related to speed. In other words, it explains that the speed of a player is not directly proportional to his endurance this is because cardiovascular endurance involves the ability of a player to sustain longer time in executing physical activities while speed is more dealing with the explosive power to accelerate within a short distance. Cardiorespiratory endurance is essential in the game of soccer since the players are required to last the full 90 minutes of the game [36]. During the game, the players are expected to do a lot of work both on and off the ball. They will make repeated runs support attacks, get into space to receive the ball, make runs with the ball, and chase back to defend, etc. The energy required to do this is supplied aerobically which requires the heart, lungs, and blood [50] system to supply oxygen to the working muscles throughout the game. Therefore, endurance is a fundamental necessity in the game of soccer. 
The VF4 indicates $50.56 \%$ of the variance in the data. It exhibits high positive loading from the task (0.694) and ego (0.747), which are related to motivation. Motivations are prerequisite elements that keep novice players in the game of soccer to perform at their best. They stressed that providing a right motivational technique can help to bring the best out of a player [37].

The VF5 highlights $55.79 \%$ of the total variability in the data. It indicates high positive loading from two components, which are ball control (0.612) and short pass (0.766). These components can be interpreted as basic skills. In a soccer game, the aim is to interchange the ball from one end to the other in order to advance, score and stay in the game. Therefore, basic skills are required for advancing and controlling the ball are essential to soccer play. Since the easiest way to advance the ball is to pass from one teammate to another and to control the ball during an exchange of pass between the teammates, acquiring specific passes and control is very imperative. Novice players are needed to be able to learn how to position themselves to receive passes, control and uses skills in receiving passes. Learning how to receive and support the ball at the same time are core competencies for novice soccer players since there is a progression of all skills in any sport and soccer is not an exception [38]. In view of this, therefore, basic skill cannot be ignored for the beginning youth soccer player.

The VF6 reveals $62.99 \%$ of the variance in the data. It shows high positive loading from agility $(0.858)$, which is much related to motor skill. Soccer game involves movement activities which are repeatedly executed to intercept, execute a pass or run within the opponents to receive a pass and score a goal. For this reason, soccer players are especially required to acquire motor skills to enable them to move and change direction at a regular interval and upon demand. Motor skill is a prerequisite for a soccer player to possess [39]. It can be explained that soccer player is beginning to develop skills and mastery in the game there is a need to acquire coordinating movement skills to response to the demand of the movement of the game.

The VF7 identifies $69.51 \%$ of the variance in the data. It projects high positive loading from shooting at the top left corner (0.772), which can be interpreted as technical skill. Soccer is a game that needs lots of multi-limb co-ordinations. That technical ability of a player helps him to develop an awareness to make a decision while striking the ball, getting the ball with either foot, passing the ball with diverse parts of the foot, rotating out of pressure, dribbling the ball at speed, controlling the ball from the air and so on. It is however shown that $90 \%$ of technical ability is acquired before the adolescent period [40]. It is the strongest differentiator between those top-level players and average players. It is important to understand why technical skill training is so important with the younger age groups of soccer players.

\section{B. Performance Source of Variation: Elite Soccer Players}

In the elite soccer players, the VF1 contributes to $12.88 \%$ of the variance in the data. It shows high positive factor loading from variation sit and reach (0.780), sergeant jump (0.635), VO2max (0.637) and age (0.752), which reveals body flexibility as it is the most contributing factor with greater loading in VF. Flexibility denotes to the range of movement in a joint. The flexibility of a joint is dependent upon the extensibility. The ability for an elite soccer player to extend without causing tissue damage and the ability of the muscle to return to its original size and shape after being stretched or shortened of the structures surrounding is very crucial in order to avoid injuries. Joint flexibility is an important factor in the performance of skills and especially in injury prevention. Professional players with greater muscle strength and lower limbs were the most regular participants of a first team representative squad over the whole season [41]. Similarly, irregularity in muscle strength, both between the left and right legs and between the leg flexors and leg extensor muscles were factors influencing injury among professional players [42]. Such interpretations would upkeep a recommendation to screen for muscle strength imbalances among youth soccer players.

The VF2 contributes to about $30.02 \%$ of the total variation in the data set. It exhibits high positive factor loading from weight (0.637), bicep (0.859), triceps (0.769), subscapular (0.847), suprailiac (0.886) and medial upper arm circumference (0.776). These components are more associated to body composition. Elite soccer teams are described by a relative variation in body size. The overall mean and standard deviation values for physique and body mass of nine professional squads were $1.77 \pm 0.15 \mathrm{~m}$ and $74.0 \pm 1.6 \mathrm{~kg}$ respectively [43]. Tall players tend to have an advantage in certain playing positions and therefore are adapted towards these roles, remarkably in goalkeeping, central defense and central attack. In a study of 65 elite Danish players, goalkeepers and central defenders were the tallest and heaviest while the mean stature and body mass of full-backs, midfield players, and forwards were similar [44].

Body composition has been currently revealed between elite's soccer players of varying positions predicting that players of certain size and shape may be appropriate for the needs of the variety of positions [43], [45]

The VF3 accounted for about $41.67 \%$ of the variation in the data set. It exhibits high positive loading from agility (0.618), $5 \mathrm{~m}$ speed $(0.712), 10 \mathrm{~m}$ speed $(0.858)$ and $20 \mathrm{~m}$ speed (0.929). These components can be interpreted as explosive power. Explosive power is considered important for performance among elite soccer players. Characteristically, competitive match-play demands an allout sprint once every $90 \mathrm{~s}$ on regular and high-intensity efforts every $30 \mathrm{~s}$ for each player [46]. Undeniably, the anaerobic activity may institute essential moments of the game and add directly to winning possession of the ball and to the scoring or conceding goals. Moreover, the relative influence of anaerobic activity is likely to be less in youth compared with adult players because of the delayed development of anaerobic metabolic pathways in adolescence.

The VF4 explains about $50.17 \%$ of the variability in the data. It reveals high negative and positive loading from the task (-0.675), ball control (0.748) and short pass (0.789) which relates to the skill mastery. It has been proving that task oriented player is recognized with higher persistence, interest, and enormous effort. Task orientation is the ability of a player to show readiness and confidence to execute certain skills [47]. The task oriented player works for the 
mastery of skills and enjoys the feeling of self-motivation and confidence. In a professional soccer game, players distinguish themselves through the application of various skills mastered to out play their opponents.

The VF5 reflects $55.83 \%$ of the total variation in the data set. It shows high negative loading from variation sit up ($0.702)$, which can be explained as core body strength. The "core" denotes to the muscles that are included in gripping the torso in place; the abdominal, lower back, and hip muscles involved in arranging the spine and pelvis. Pelvic firmness is the ability of the trunk and pelvic muscles to keep the spine and pelvis in its ideal position during sporting activity. When these structures are kept in an optimal arrangement, then the muscles and joints of the lower limbs are able to work effectively [48]. The muscles of the lumbopelvic hip complex perform a vital role in coordinating movement. In a soccer game, core strength not only can influence the athlete's ability to move fast and alter direction quickly but is essential to the capability to win tackles. Core muscles are imperative for a soccer player as they function as a medium for endurance, posture, strength, power, coordination and decreasing likelihood of injury.

The VF6 contributes to $62.57 \%$ of the overall variation in the data. It shows high positive loading from shooting at the top left corner (0.749) and shooting at the top right corner (0.660), which can be described as technical skill. Technical skills delineate the true players, who are looking for more than just having fun, but wanting to become better and always striving for more [40]. These skills are the basis of a becoming a good or great soccer player, depending on how much work and effort a player puts into it. The technical ability of a player helps him to develop an awareness to make a decision while striking the ball, getting the ball with either foot, passing the ball with diverse parts of the foot, rotating out of pressure, dribbling the ball at speed, controlling the ball from the air. These factors describe and differentiate players based on their expertise. Elite soccer players possess higher technical skills in comparison to their novice counterpart.

The VF7 describes $72.58 \%$ of the variance in the data set. It exhibits high positive loading from height (0.849) and sitting height (0.873) which can be interpreted as body height. For the attainment of favourable results in soccer, physical characteristics have been identified as the most likely to predispositions for positional roles with taller players being the most suitable for central defensive positions and the 'target' player among the strikers or forwards. This factor may be linked with pre-selection of early matures for key positional roles, where body size rather than playing skills provides an advantage [43], [45].

\section{CONCLUSION}

This study aims to identify the variables that are essential for the performance of soccer game for both elite and novice players. To achieve the aim of this study, we employed 84 elite's soccer players and 100 novice players from eight soccer academies in Malaysia. We subjected the participants to standard anthropometric, fitness; skills related performance testing and responded to the questionnaire in mastery and performance. We utilized PCA to determine the most crucial variables pertinent to the requirement of the game in relation to the level of expertise of the players. The initial PCA analysis shows seven components out of 26 as the most significant for both elite and novice soccer players with a considerable higher eigenvalue. Moreover, the PCA after varimax rotation stressed seven PCs for elite and novice players respectively. Each of the seven components contains VF selected based on their higher factor loading and that distinguish the players on their expertise. The elite's players VFs discloses body flexibility, body composition, explosive power, mastery of skills, core body strength, technical skills and body height as essential requirements. The VFs for novice players indicated physical characteristics, body composition, endurance, motivation, basic skills, motor skills and technical skills as most needful. Our discoveries proposed that investigation of variables that are essential in the performance of soccer [49] in connection with the level of expertise of the players might be of help to the coaches, team managers and other stakeholders in assessing the impacts of a particular preparatory program. It might likewise be useful to the trainers in focusing on essential performance indicators in the game which can save time, energy and cost.

\section{ACKNOWLEDGMENT}

The researchers wish to acknowledge the coaches and managers of Bandar Penawar and Bukit Jalil Sports Academy Malaysia for their support to the accomplishment of this study.

\section{REFERENCES}

[1] T. Stølen, K. Chamari, C. Castagna, and U. Wisløff, "Physiology of soccer," Sports Medicine, vol. 35, pp. 501-536, Jun. 2005.

[2] C. Carling, A. M. Williams, and T. Reilly, Handbook of Soccer Match Analysis: A Systematic Approach to Improving Performance, London, United Kingdom: Psychology Press, 2005.

[3] G. Dona, E. Preatoni, C. Cobelli, R. Rodano, and A. J. Harrison, "Application of functional principal component analysis in race walking: An emerging methodology," Sports Biomechanics, vol. 8, pp. 284-301, Nov. 2009.

[4] P. B. Gastin, D. Meyer, E. Huntsman, and J. Cook, "Increase in injury risk with low body mass and aerobic-running fitness in elite Australian football," International Journal of Sports Physiology and Performance, vol. 10, pp. 458-463, May 2015.

[5] A. Nevill, R. Holder, and A. Watts, "The changing shape of "successful" professional footballers," Journal of Sports Sciences, vol. 27, pp. 419-426, Mar. 2009.

[6] P. Federolf, R. Reid, M. Gilgien, P. Haugen, and G. Smith, "The application of principal component analysis to quantify technique in sports," Scandinavian Journal of Medicine and Science in Sports, vol. 24, pp. 491-499, Jun. 2014.

[7] M. Svensson and B. Drust, "Testing soccer players," Journal of Sports Sciences, vol. 23, pp. 601-618, Jun. 2005.

[8] M. R. Abdullah, R. M. Musa, A. B. H. M. Maliki, N. A. Kosni, and P. K. Suppiah, "Role of psychological factors on the performance of elite soccer players" Journal of Physical Education and Sport, vol. 16, pp. 170-176, Mar. 2016.

[9] H. Juahir, S. M. Zain, M. K. Yusoff, T. T. Hanidza, A. M. Armi, M. E. Toriman, and M. Mokhtar, "Spatial water quality assessment of Langat River Basin (Malaysia) using environmetric techniques," Environmental Monitoring and Assessment, vol. 173, pp. 625-641, Feb. 2011.

[10] D. Dominick, H. Juahir, M. T. Latif, S. M. Zain, and A. Z. Aris, "Spatial assessment of air quality patterns in Malaysia using multivariate analysis," Atmospheric Environment, vol. 60, pp. 172181, Dec. 2012.

[11] S. N. S. A. Mutalib, H. Juahir, A. Azid, S. M. Sharif, M. T. Latif, A. Z. Aris, S. M. Zain, and D. Dominick, "Spatial and temporal air quality pattern recognition using environmetric techniques: A case 
study in Malaysia," Environmental Science: Processes and Impacts, vol. 15, pp. 1717-1728, Jun. 2013.

[12] L. Mellemkjaer, J. Christensen, K. Frederiksen, J. L. Baker, A. Olsen, T. I. A. Sørensen, and A. Tjønneland, "Leg length, sitting height and postmenopausal breast cancer risk," British Journal of Cancer, vol. 107, pp. 165-168, Jun. 2012.

[13] D. Čular, M. Milić, A. Bilić-Pavlinović, R. Katić, G. Kuvačić, and J. Vrdoljak, "Somatotype of young Taekwondo competitors," Research in Physical Education, Sport and Health, vol. 2, pp. 27-33, Jan. 2013.

[14] M. J. Marfell-Jones, A. D. Stewart, and J. H de Ridder, International Standards for Anthropometric Assessment, Wellington, New Zealand: International Society for the Advancement of Kinanthropometry, 2012.

[15] T. Noguchi, S. Demura, and K. Takahashi, "Relationships between sit-ups and abdominal flexion strength tests and the thickness of each abdominal muscle," Advances in Physical Education, vol. 3, pp. 8488, May 2013.

[16] L. Leger and C. Gadoury, "Validity of the $20 \mathrm{~m}$ shuttle run test with 1 min stages to predict $\mathrm{VO}_{2} \max$ in adults," Canadian Journal of Sport Sciences, vol. 14, pp. 21-26, Mar. 1989.

[17] M. Russell and E. Tooley, "Anthropometric and performance characteristics of young male soccer players competing in the UK," Serbian Journal of Sports Sciences, vol. 5, pp. 155-162, Dec. 2011.

[18] T. R. Baechle and R. W. Earle, Essentials of Strength Training and Conditioning, 3rd ed., T. R. Baechle and R. W. Earle, Ed. Illinois, USA: Human Kinetics, 2008.

[19] D. Mayorga-Vega, R. Merino-Marban, and J. Viciana, "Criterionrelated validity of sit-and-reach tests for estimating hamstring and lumbar extensibility: A meta-analysis," Journal of Sports Science and Medicine, vol. 13, pp. 1-14, Jan. 2014.

[20] J. Hoffman, Norms for Fitness, Performance, and Health, Illinois, USA: Human Kinetics, 2006.

[21] J. Tanner, Growth at Adolescence, 2nd ed., Oxford, UK: Balckwell Scientific Publications, 1962.

[22] D. Rösch, R. Hodgson, L. Peterson, T. Graf-Baumann, A. Junge, J. Chomiak, and J. Dvorak, "Assessment and evaluation of football performance," American Journal of Sports Medicine, vol. 28, pp. 2939, Sep. 2000.

[23] J. L. Duda, "Relationship between task and ego orientation and the perceived purpose of sport among high school athletes," Journal of Sport and Exercise Psychology, vol. 11, pp. 318-335, Sep. 1989.

[24] A. Andasuryani, Y. A. Purwanto, I. W. Budiastra, and K. Syamsu, "Determination of catechin content in gambir powder from dried gambir leaves quickly using FT NIR PLS model," International Journal on Advanced Science, Engineering and Information Technology, vol. 4, pp. 303-307, Aug. 2014.

[25] V. Simeonov, J. W. Einax, I. Stanimirova, and J. Kraft, "Environmetric modeling and interpretation of river water monitoring data," Analytical and Bioanalytical Chemistry, vol. 374, pp. 898-905, Nov. 2002

[26] B. G. Tabachnick and L. S. Fidell, Using Multivariate Statistics, 4th Ed. New York, USA: Harper and Row, 2001.

[27] M. S. Bartlett, "Tests of significance in factor analysis," British Journal of Statistical Psychology, vol. 3, pp. 77-85, Jun. 1950.

[28] A. Field, Discovering Statistics Using SPSS for Windows: Advanced Techniques for Beginners (Introducing Statistical Methods Series), London, UK: SAGE Publications, 2000.

[29] J. O. Kim and C. W. Mueller, Introduction to Factor Analysis: What It Is and How To Do It (Quantitative Applications in the Social Sciences), California, USA: SAGE Publications, 1978.

[30] H. F. Kaiser, "The varimax criterion for analytic rotation in factor analysis," Psychometrika, vol. 23, pp. 187-200, Sep. 1958.

[31] C. W. Liu, K. H. Lin, and Y. M. Kuo, "Application of factor analysis in the assessment of groundwater quality in a blackfoot disease area in Taiwan," Science of the Total Environment, vol. 313, pp. 77-89, Sep. 2003.

[32] J. Pion, V. Segers, J. Fransen, G. Debuyck, D. Deprez, L. Haerens, R. Vaeyens, R. Philippaerts, and M. Lenoir, "Generic anthropometric and performance characteristics among elite adolescent boys in nine different sports," European Journal of Sport Science, vol. 15, pp. 357-366, Jul. 2015
[33] M. Strzala and A. Tyka, "Physical endurance, somatic indices and swimming technique parameters as determinants of front crawl swimming speed at short distances in young swimmers," Medicina Sportiva, vol. 13, pp. 99-107, Jun. 2009.

[34] T. Vestberg, R. Gustafson, L. Maurex, M. Ingvar, and P. Petrovic, "Executive functions predict the success of top-soccer players," PloS One, vol. 7, pp. 1-5, Apr. 2012.

[35] J. Rak, M. Erceg, M. Milić, Z. Grgantov, and H. Sivrić, "Interpositional differences in somatotype among young soccer players," in Proc. FIS Communications'14, 2014, p. 103-110.

[36] K. Halder, A. Pathak, T. OS, and M. S. A. Chatterjee, "Physical and physiological comparison between indian female college basketball players and sedentary students," Advances in Applied Physiology, vol. 1, pp. 18-23, 2016.

[37] A. Najah and R. B. Rejeb, "The psychological profile of youth male soccer players in different playing positions," Advances in Physical Education, vol. 5, pp. 161-169, Jul. 2015.

[38] M. D. Ahmed, "Assessment of goal orientation among adolescent athletes with regard to their participation in recreation and leisure activities: A factor analysis approach," Journal of Physical Education and Sports Management, vol. 1, pp. 81-91, Mar. 2014.

[39] V. Martínez-Lagunas, M. Niessen, and U. Hartmann, "Women's football: Player characteristics and demands of the game," Journal of Sport and Health Science, vol. 3, pp. 258-272, Dec. 2014.

[40] A. Claessens, "Talent detection and talent development: kinanthropometric issues," Acta Kinesiologiae Universitatis Tartuensis, vol. 4, pp. 47-64, Jan. 1999.

[41] M. R. Abdullah, A. B. H. M. Maliki, R. M. Musa, N. A. Kosni, and H. Juahir, "Intelligent prediction of soccer technical skill on youth soccer player's relative performance using multivariate analysis and artificial neural network techniques," International Journal on Advanced Science, Engineering and Information Technology, vol. 6, Sep. 2016.

[42] T. Dos' Santos, C. Thomas, P. A. Jones, and P. Comfort, "Assessing muscle strength asymmetry via a unilateral stance isometric midthigh pull," International Journal of Sports Physiology and Performance, pp. 1-24, Aug. 2016.

[43] T. Reilly, What Research Tells the Coach About Soccer, Washington, USA: American Alliance for Health, Physical Education, Recreation and Dance, 1979.

[44] R. Morgans, D. Adams, R. Mullen, J. Sacramento, C. McLellan, M. Williams, B. Gerrard, and H. MacRae, "A comparison of physical and technical match performance of a team competing in the English championship league and then the English premier league following promotion," International Journal of Sports Science and Coaching, vol. 10, pp. 543-550, Jun. 2015.

[45] A. Pedretti, A. Pedretti, J. B. de Oliveira Fernandes, A. N. C. Rebelo, and A. F. T. Seabra, "The relative age effects in young soccer players and it relations with the competitive level, specific position, morphological characteristics, physical fitness and technical skills,' Pensar a Prática, vol. 19, pp. 372-385, Jun. 2016.

[46] D. L. Johnson and R. Bahamonde, "Power output estimate in university athletes," Journal of Strength and Conditioning Research, vol. 10, pp. 161-166, Aug. 1996.

[47] N. Mascret, A. J. Elliot, and F. Cury, "Extending the $3 \times 2$ achievement goal model to the sport domain: The $3 \times 2$ achievement goal questionnaire for sport," Psychology of Sport and Exercise, vol. 17, pp. 7-14, Mar. 2015.

[48] C. Williams, "Core training: Partner-based medicine ball training," NSCA's Performance Training Journal, vol. 10, pp. 9-16, Oct./Nov. 2011.

[49] M. R. Abdullah, A. B. H. M. Maliki, R. M. Musa, N. A. Kosni, and H. Juahir, "Intelligent prediction of soccer technical skill on youth soccer player's relative performance using multivariate analysis and artificial neural network techniques," International Journal on Advanced Science, Engineering and Information Technology, vol. 6, pp. 668-674, Oct. 2016

[50] S. Sulaiman, Z. A. Manaf, and M. R. Shahril, "Compliance to dietary counselling in controlling blood lipid and its barriers among dyslipidemic individuals," International Journal on Advanced Science, Engineering and Information Technology, vol. 6, pp. 697702 , Oct. 2016 